\title{
Rent Seeking in Hierarchical Firms
}

\author{
by \\ Gil S. Epstein \\ Department of Economics, Bar-Ilan University, Israel \\ CEPR, London and IZA, Bonn \\ and \\ Ira N. Gang \\ Rutgers University, USA \\ June 2, 2002
}

\begin{abstract}
Hierarchical firms are enterprises with rigid internal job ladders. We examine the state enterprise as the prototypical hierarchical firm. In the state enterprise, promotion of employees through the internal hierarchy is determined by the workers' allocation of time between rent seeking and productive activity. Our model shows that given the incentive structure of the state enterprise we tend to see less productive and more adept rent seekers at senior management positions in such firms. Moreover, as we move up the firm's hierarchy, a decline in the productivity levels of the workers will be observed.
\end{abstract}

Key words: Inefficiency, rent seeking, hierarchical firms, promotion, internal job ladder, state enterprise JEL classification: D2, D72, L32.

*Gil S. Epstein, Economics Department, Bar-Ilan University, 52900 Ramat-Gan, Israel. Fax: +972 3 535-3180, E-mail: epsteig@mail.biu.ac.il.

*Ira N. Gang, Economics Department, Rutgers University, 75 Hamilton St., New Brunswick NJ 08901-1248 USA. Fax: +1 732 932-7416, Email: gang@economics.rutgers.edu.

We are grateful to Arye Hillman for many helpful suggestions and comments.

(C)Gil S. Epstein and Ira N. Gang. All Rights Reserved. 


\section{Introduction}

Hierarchical firms are enterprises with rigid internal job ladders. We examine the state enterprise as the prototypical hierarchical firm. In the private sector, profit maximization and the discipline it imposes is a reasonable first assumption in analyzing firm behavior. For state enterprises, public sector firms, government establishments and other similarly structured organizations the goal is more diffuse. The absence of private owners and firm accountability may result in a greater part of surpluses (rents) being found within the firm. Moreover, without clear goals it is more difficult to analyze a persons contribution to the firm, and it is more difficult to objectively determine who should be promoted and who should not be. The presence of the rents affects the incentives to seek promotion in the firm. The question we look at in this paper is whether those more adept at rent seeking have an internal advantage in seeking promotion within state enterprises. The answer is in general positive.

The firm in our model has a pyramid structure: the number of employees declines at higher levels of the internal hierarchy, and one incumbent is situated at the top-level of the hierarchy. The internal rents that are distributed within the firm increase with the level of the hierarchy at which employees are positioned. Internal rent seeking contests take place to win promotion, and thereby to secure increased rents. When less productive employees succeed in having themselves promoted, the total rents within the firm decrease, and consequently more productive workers have a decreased incentive to seek promotion. Less efficient senior management diminishes the incentive of the more productive employees to seek promotion, since the more productive employees have more reason to allocate time to production at their present hierarchical level within the firm. The problem confronting more productive employees is indeed whether it is worth their while participating in the internal rent seeking contests, since their comparative advantage is in productive activity rather in the types of favor-seeking activities which underlie success in the internal firm contests for promotion.

A substantial literature discusses how managers come up via competition through the ranks of the firm (see for example Beckmann (1978) and Rosen (1986)). Whereas Rosen's contests are directed at assuring efficiency, in our model efficiency is 
not ensured by the outcomes of the contests for promotion. This paper emphasizes how, in this same context, rents figure prominently in hierarchical firms and how comparative advantage in rent seeking influences promotion prospects.

\section{The Model}

Employees are risk neutral and seek to maximize expected income defined over three periods. The firm also has three hierarchical levels. Employees may seek promotion from level 3 to level 2 and then to level 1, with contests taking place once each period. Contesting promotion is personally costly in time and income foregone, since productive work is directly rewarded, not the time spent in (self) promotion activities. Workers have different comparative advantages in ingratiating themselves via rent seeking and in contributing to the value of the firm's output. An individual's income is determined by his productivity, plus the rents that accrue at different rungs of the hierarchy.

The question is: who is promoted to senior management in the state enterprise? That is, is there adverse selection in the promotion contests?.

If the rewards from climbing the ladder in the hierarchy of the state enterprise are high but not high enough, less productive employees will be on higher rungs of the firm, reducing efficiency and internal rents that are available for division among the firm's employees.

Our model also considers the consequences of the internal hierarchical structure of the enterprise. We compare two types of firms, one with more rungs than the other. ${ }^{1}$ We show that the firm with more rungs is, on average, less efficient, because at each contest level there is a higher likelihood that less productive employees (but better rent seekers) win promotion. Smaller hierarchies are, conversely, on average,

\footnotetext{
${ }^{1}$ Firm structure has been analyzed in different ways, for example, the efficiency of production in different types of firm structures (Williamson (1967) and Keren and Levhari $(1978,1989)$ ), in terms of estimating an optimal size of structure (Radner (1993)) and in terms of the probability of choosing the right type of project for a firm to concentrate on (see Sah and Stiglitz (1986)).
} 
more efficient. ${ }^{2}$ However, in a firm with fewer rungs, all employees expend more time in rent seeking to facilitate promotion.

There are four employees and three time periods. Employees are divided into three groups: workers, vice-presidents and the president. In the first period all employees are on the same rung in the firm and are "workers". The workers are divided into two groups (divisions or departments within the firm), with two workers in each group. In the first period, while working in the first rung, employees can choose to compete for the position of vice-president. Those who succeed (one vicepresident for each group) start in the new position in period two. The workers who lose (or did not contest) continue as workers in the second and third periods. Then, in the second period, the employees who succeeded in reaching the post of vice-president compete for the position of president. The employee who wins this competition enters the office in the third period.

The income of each employee per unit of labor is: $w_{i}$ if the employee is on the first rung (i.e., a worker), $v_{i}$ if the employee is on the second rung (vice-president) and $p_{i}$ if the employee is the president (to simplify the notation we denote the workers in first group by the index $i=1,2$ and those in the second group by $i=a, b$ ). Income per unit of labor is an increasing function of an individual's productivity, and equals the productivity level plus the income from rent seeking.

Each individual has an endowment of labor time normalized to unity, which is allocated between productive activities $\mathrm{Ai}$, and time $\mathrm{L}_{\mathrm{i}}$ spent in rent seeking:

$$
A_{i}+L_{i}=1
$$

We can normalize the absolute efficiency in rent seeking to unity. $\mathrm{w}_{\mathrm{i}}$ then defines the absolute and relative productive efficiency for one unit of time; $v_{i}$ and $p_{i}$ are similarly defined.

Without loss of generality, let

2 This latter result complements Williamson's (1967) well-known contention that low-level hierarchical organizations are more efficient. In Williamson's case this is because of greater internal goal consistency and the subsequent lesser need for expending resources on monitoring. 


$$
w_{1}>w_{2} \text { and } w_{a}>w_{b}
$$

with the same type of relationship holding for $v_{i}$ and $p_{i}$

$$
\text { if } w_{i}>w_{j} \text { then } v_{i}>v_{j} \text { and } p_{i}>p_{j} \text { for all } i \neq j \text {. }
$$

This implies that a productive employee is always more productive regardless of his position in the hierarchy.

The wage is competitively determined per efficiency-normalized unit of labor supplied. An employee's income is negatively related to time spent in rent seeking activities.

In order to simplify, and without loss of generality, let the discount rate be one. In period one the worker allocates time between seeking the position of vice-president and productive activity, yielding income:

$$
I_{i}=w_{i}\left(1-L_{i}\right)
$$

A vice-president seeks the position of president, and has income:

$$
I_{i}=v_{i}\left(1-L_{i}\right)
$$

The president does not seek a better position, and has income:

$$
I_{i}=p_{i}
$$

Let the contest-success function (Hirshleifer 1989), be determined by a nondiscrimination rule (Tullock (1980), Hillman and Riley (1989)), such that $i$ 's probability of success in competing against $j$ is given by:

$$
\operatorname{Pr} o b_{i}\left(L_{i}, L_{j}\right)=\frac{L_{i}}{L_{i}+L_{j}} \quad \forall i \neq j
$$


In order to determine an individual's optimal time allocation, we start from the second period (for an illustration see figure 1).

\section{Second period}

Lets us examine individual number 1. This individual is a vice-president in the second period, and his expected income depends on whether worker $a$ or worker $b$ has gained the other position of vice-president. Worker $a$ is the parallel vice-president to worker number 1 , so individual 1's expected income in the second period is:

$$
\begin{gathered}
E\left(I_{1}^{2} \mid a\right)=v_{1}\left(1-L_{1}^{2}\right)+v_{1}\left(1-\frac{L_{1}^{2}}{L_{1}^{2}+L_{a}^{2}}\right)+p_{1} \frac{L_{1}^{2}}{L_{1}^{2}+L_{a}^{2}}= \\
=v_{1}\left(2-L_{1}^{2}\right)+\left(p_{1}-v_{1}\right) \frac{L_{1}^{2}}{L_{1}^{2}+L_{a}^{2}}
\end{gathered}
$$

$L_{1}^{2}$ is individual 1's rent seeking in period 2. Thus, in the third period individual 1

earns either $\mathrm{v}_{1}$, as vice-president, with a probability of $\frac{L_{2}}{L_{1}+L_{2}}=1-\frac{L_{1}}{L_{1}+L_{2}}$ or becomes president in period number three with a probability of $\frac{L_{1}}{L_{1}+L_{2}}$, and earns $p_{i}$.

On the other hand, the expected income of individual $a$ given that individual number 1 is vice-president is:

$$
E\left(I_{a}^{2} \mid 1\right)=v_{a}\left(1-L_{a}^{2}\right)+v_{a} \frac{L_{1}^{2}}{L_{1}^{2}+L_{a}^{2}}+p_{a} \frac{L_{a}^{2}}{L_{1}^{2}+L_{a}^{2}}
$$

Each vice-president maximizes his expected income by choosing the extent of his rent seeking ${ }^{3}$. Expected income is determined by the Nash equilibrium rent seeking choices. For vice-president number 1:

$$
\frac{\partial E\left(I_{1}^{2} \mid a\right)}{\partial L_{1}^{2}}=-v_{1}+\left(p_{1}-v_{1}\right) \frac{L_{a}^{2}}{\left(L_{1}^{2}+L_{a}^{2}\right)^{2}}
$$

3 The result would not change even if an individual could change the level of investment during the process of the contest when receiving new information (see Epstein (1996a, 1996b). 
Similarly, for vice- president $a$ :

$$
\frac{\partial E\left(I_{a}^{2} \mid 1\right)}{\partial L_{a}^{2}}=-v_{a}+\left(p_{a}-v_{a}\right) \frac{L_{1}^{2}}{\left(L_{1}^{2}+L_{a}^{2}\right)^{2}}
$$

Setting (9) and (10) to zero and solving yields:

$$
L_{1}^{2}=\frac{\left(p_{a}-v_{a}\right)\left(p_{1}-v_{1}\right)^{2} v_{a}}{\left(\left(p_{1}-v_{1}\right) v_{a}+\left(p_{a}-v_{a}\right) v_{1}\right)^{2}}
$$

and

$$
L_{a}^{2}=\frac{\left(p_{1}-v_{1}\right)\left(p_{a}-v_{a}\right)^{2} v_{1}}{\left(\left(p_{1}-v_{1}\right) v_{a}+\left(p_{a}-v_{a}\right) v_{1}\right)^{2}}
$$

We can now compute the probability of each individual reaching the position of president:

$$
\begin{aligned}
& \operatorname{Pr} o b_{1}\left(L_{1}^{2}, L_{a}^{2}\right)=\frac{L_{1}^{2}}{L_{1}^{2}+L_{a}^{2}}=\frac{\left(p_{1}-v_{1}\right) v_{a}}{\left(p_{1}-v_{1}\right) v_{a}+\left(p_{a}-v_{a}\right) v_{1}} \\
& \text { and } \\
& \operatorname{Pr} o b_{a}\left(L_{a}^{2}, L_{1}^{2}\right)=\frac{L_{a}^{2}}{L_{1}^{2}+L_{a}^{2}}=\frac{\left(p_{a}-v_{a}\right) v_{1}}{\left(p_{1}-v_{1}\right) v_{a}+\left(p_{a}-v_{a}\right) v_{1}}
\end{aligned}
$$

In order to gain a better understanding of these results, let us look at the ratio of the two employee's rent seeking activities. From equation (13) the ratio of the rent seeking values equals the ratio of the probabilities of reaching the position of president. An increase in the ratio means that the relative probability has increased.

$$
\frac{L_{1}^{2}}{L_{a}^{2}}=\frac{\left(p_{1}-v_{1}\right) v_{a}}{\left(p_{a}-v_{a}\right) v_{1}}=\frac{\operatorname{Pr} o b_{1}(.)}{\operatorname{Pr} o b_{a}(.)}
$$


The question is now: who invests more in privilege seeking activities? In answer to this question, we investigate whether the ratio defined in equation (14) increases or decreases with an increase in productivity of one individual $\left(v_{l}\right.$ or $\left.v_{a}\right)$, while holding the productivity of the other constant. We have:

$$
\frac{\partial\left(\frac{L_{1}^{2}}{L_{a}^{2}}\right)}{\partial v_{1}}=\frac{v_{a}}{\left(p_{a}-v_{a}\right)} \frac{\left(\frac{\partial p_{1}}{\partial v_{1}} v_{1}-p_{1}\right)}{v_{1}^{2}}
$$

which rests on the sign of:

$$
\left(\frac{\partial p_{1}}{\partial v_{1}} v_{1}-p_{1}\right)
$$

There are three cases we are obliged to consider:

Case 1: $p_{1}=p_{a}\left(p_{1}=p_{a}>\operatorname{Max}\left\{v_{a}, v_{1}\right\}\right)$. Here the president's income is independent of his productivity level, and we can conclude that

Less productive employees invest more time in rent seeking activities and have a higher probability of being the president of a public firm.

This result is somewhat similar to the result presented in Epstein, Hillman and Ursprung (1999). These authors present a one period model where a contest takes place in order to win a prize. Investment, in order to affect the outcome of the contest, depends on time consumption and thus is a function of the contestants' productivity levels. The prize is fixed and equal for all contestants. These authors show that the less productive invest more time in privilege seeking activities and so have a higher probability of winning the contest.

Case 2: $p_{a}<p_{1}, v_{a}<v_{1}$ and $0<\frac{\partial p_{1}}{\partial v_{1}} \frac{v_{1}}{p_{1}}<1$. If a worker is more productive as vice-president, he will be more productive as president. Moreover, this condition also 
shows that, for the productive individual, the elasticity of productivity of the president in relation to an increase in productivity of that individual as a vice-president is less than one. In other words, if an individual is more productive as vice-president, he will be more productive as president. An increase in productivity of an individual as vicepresident then increases the productivity of the same individual as president with a decreasing margin.

Let us look at two examples of a relationship between the productivity level of a vice-president and the productivity level of the president where the elasticity is less than one:

Example \#1: $p_{i}=\left(v_{i}+d\right)^{2}$. For all individuals, $v_{i}^{2}<d^{2} ;$ the more productive workers invest less in rent seeking.

Example \#2: $p_{i}=c v_{i}+d v_{i}^{1 / 2}(d$ and $c>0)$; in this case, once again, more productive workers invest less in rent seeking.

In the above two examples, the productivity of the president increases with the productivity of the vice-president. The question is, what happens to the productivity of an employee who moves up a rung in the firm's hierarchy? The answer is again that:

Less productive employees invest more time in privilege seeking activities and have a higher probability of being the president of the public firm.

Case 3: $p_{a}<p_{1}, v_{a}<v_{1}$ and $1<\frac{\partial p_{1}}{\partial v_{1}} \frac{v_{1}}{p_{1}}$ i.e., the elasticity of productivity of a president with respect to a change in the productivity of the vice-president is larger than one. This case is complementary to Case 2. Here, when a worker is more productive as vice-president, his productivity increases as president by more than the increase in productivity of vice-president. An example is the complementary case of the first example in Case 2: $p_{i}=\left(v_{i}+d\right)^{2}$ for all individuals that it holds $v_{i}^{2}>d^{2}$. Here, 
More productive employees invest more time in rent seeking and have a higher probability of being the president of the public firm.

Typically in state enterprises the ratio of the compensation of a top manager and the wage of a low-level worker is small compared to the private sector. Moreover, in many cases the wage does not depend on the productivity level at all.

We now calculate the expected income level of two employees given the different possibilities of vice-presidents competing with one another. If employee 1 and employee a are vice-presidents, the expected income of individual 1 in time period 2 is given (by using equations (13) and (14)):

$$
E\left(I_{1}^{2} \mid a\right)=v_{1}\left(2-\frac{\left(p_{1}-v_{1}\right)^{2}\left(p_{a}-v_{a}\right) v_{a}}{\left(\left(p_{a}-v_{a}\right) v_{1}+\left(p_{1}-v_{1}\right) v_{a}\right)^{2}}\right)+\frac{\left(p_{1}-v_{1}\right)^{2} v_{a}}{\left(\left(p_{a}-v_{a}\right) v_{1}+\left(p_{1}-v_{1}\right) v_{a}\right)}
$$

Similarly,

$$
E\left(I_{a}^{2} \mid 1\right)=v_{a}\left(2-\frac{\left(p_{a}-v_{a}\right)^{2}\left(p_{1}-v_{1}\right) v_{1}}{\left(\left(p_{a}-v_{a}\right) v_{1}+\left(p_{1}-v_{1}\right) v_{a}\right)^{2}}\right)+\frac{\left(p_{a}-v_{a}\right)^{2} v_{1}}{\left(\left(p_{a}-v_{a}\right) v_{1}+\left(p_{1}-v_{1}\right) v_{a}\right)}
$$

and,

$$
E\left(I_{1}^{2} \mid b\right)=v_{1}\left(2-L_{1}^{2}\right)+\left(p_{1}-v_{1}\right) \frac{L_{1}^{2}}{L_{1}^{2}+L_{b}^{2}}
$$




$$
E\left(I_{1}^{2} \mid b\right)=v_{1}\left(2-\frac{\left(p_{1}-v_{1}\right)^{2}\left(p_{b}-v_{b}\right) v_{b}}{\left(\left(p_{b}-v_{b}\right) v_{1}+\left(p_{1}-v_{1}\right) v_{b}\right)^{2}}\right)+\frac{\left(p_{1}-v_{1}\right)^{2} v_{b}}{\left(\left(p_{b}-v_{b}\right) v_{1}+\left(p_{1}-v_{1}\right) v_{b}\right)}
$$

We conclude, therefore, given that individual number 1 has reached the vicepresidential post, his expected income is:

$$
E\left(I_{1}^{2}\right)=\frac{L_{a}^{1}}{L_{a}^{1}+L_{b}^{1}} E\left(I_{1}^{2} \mid a\right)+\frac{L_{b}^{1}}{L_{a}^{1}+L_{b}^{1}} E\left(I_{1}^{2} \mid b\right)
$$

In a similar way we calculate the values of $E\left(I_{2}^{2}\right), E\left(I_{a}^{2}\right)$ and $E\left(I_{b}^{2}\right)$.

\section{First period}

In the previous subsection we solved the problem of the individual who has reached the second period and became vice-president. In this section we analyze the case of the worker during the first period who is looking forward to the second and third periods.

In time period one, individual 1's problem may be written as follows:

$$
E\left(I_{1}^{1}\right)=w_{1}\left(1-L_{1}^{1}\right)+\frac{L_{2}^{1}}{L_{1}^{1}+L_{2}^{1}} 2 w_{1}+E\left(I_{1}^{2}\right) \frac{L_{1}^{1}}{L_{1}^{1}+L_{2}^{1}}
$$

namely, expected income in time period one equals the time spent working in period number $1, w_{1}\left(1-L_{1}^{1}\right)$, plus the expected value of future income. The expected value of future income from time period two is divided into two parts: first, the worker does not attain the position of vice-president and so the next two periods gets an income of $w_{1}$. This occurs with probability $\frac{L_{2}^{1}}{L_{2}^{1}+L_{1}^{1}}=1-\frac{L_{1}^{1}}{L_{2}^{1}+L_{1}^{1}}$.

Second, the employee wins the contest and attains the position of vice-president. The probability for this happening is $\frac{L_{1}^{1}}{L_{2}^{1}+L_{1}^{1}}$ and the expected income is as we calculated in the previous section, $E\left(I_{1}^{2}\right)$. We may rewrite worker number 1's expected income in period number 1 (equation (22)), as follows: 


$$
E\left(I_{1}^{1}\right)=w_{1}\left(3-L_{1}^{1}\right)+\left[E\left(I_{1}^{2}\right)-2 w_{1}\right] \frac{L_{1}^{1}}{L_{1}^{1}+L_{2}^{1}}
$$

Notice that given our assumptions it holds that $E\left(I_{1}^{2}\right)-2 w_{1}>0$

In a similar way we may write the expected income of the other individuals, $2, a$ and $b$, by $E\left(I_{2}^{1}\right), E\left(I_{a}^{1}\right)$ and $E\left(I_{b}^{1}\right)$, respectively.

Given the values of $E\left(I_{2}^{2}\right)$ and $E\left(I_{1}^{2}\right)$, we may calculate the optimal values of $L_{1}^{1}$ and $L_{2}^{1}$ at the Nash equilibrium. The calculations are precisely those of the previous section regarding the values of $L_{1}^{2}$ and $L_{2}^{2}$ at the Nash equilibrium given that the workers have reached the post of vice-president (in a similar way we may calculate $L_{a}^{1}$ and $\left.L_{b}^{1}\right)$ :

$$
L_{1}^{1}=\frac{\left[E\left(I_{2}^{2}\right)-2 w_{2}\right]\left[E\left(I_{1}^{2}\right)-2 w_{1}\right]^{2} w_{2}}{\left(\left[E\left(I_{1}^{2}\right)-2 w_{1}\right] w_{2}+\left[E\left(I_{2}^{2}\right)-2 w_{2}\right] w_{1}\right)^{2}}
$$

and

$$
L_{2}^{1}=\frac{\left[E\left(I_{1}^{2}\right)-2 w_{1}\right]\left[E\left(I_{2}^{2}\right)-2 w_{2}\right]^{2} w_{1}}{\left(\left[E\left(I_{2}^{2}\right)-2 w_{2}\right] w_{1}+\left[E\left(I_{1}^{2}\right)-2 w_{1}\right] w_{2}\right)^{2}}
$$

Again, we can examine the ratio of the values of the levels of the privilege seeking activities of the two employees. Notice that from equation (13) the ratio of the levels of the rent seeking activities equals the ratio of the probabilities of reaching the position of president,

$$
\frac{L_{1}^{1}}{L_{2}^{1}}=\frac{\left[E\left(I_{1}^{2}\right)-2 w_{1}\right] w_{2}}{\left[E\left(I_{2}^{2}\right)-2 w_{2}\right] w_{1}}
$$

Notice that $E\left(I_{i}^{2}\right)-2 w_{i}>0$ and that $E\left(I_{i}^{2}\right)>v_{i}$.

The results that now follow are similar to that of an employee who has a two period horizon and an objective in period one to become vice-president in period two. The employee wants, first of all, to be vice-president. If he does not attain this position he will not be able to attain the position of president. From the Tullock function, we know that it will always hold that if $E\left(I_{i}^{2}\right)>v_{i}$ and if $v_{i}>v_{j}$ then, $E\left(I_{i}^{2}\right)>E\left(I_{j}^{2}\right) \forall i \neq j$. 
We have now:

$$
\frac{\partial\left(\frac{L_{1}^{1}}{L_{2}^{1}}\right)}{\partial w_{1}}=\frac{w_{2}}{E\left(I_{2}^{2}\right)-2 w_{2}} \frac{\left(\frac{\partial E\left(I_{1}^{2}\right)}{\partial w_{1}} w_{1}-E\left(I_{1}^{2}\right)\right)}{w_{1}^{2}}
$$

Again, there are three different cases. In two of the cases (27) is negative and in one case positive. When the worker only looks one period ahead:

$$
\frac{\partial\left(\frac{L_{1}^{1}}{L_{2}^{1}}\right)}{\partial w_{1}}=\frac{w_{2}}{v_{2}-w_{2}} \frac{\left(\frac{\partial v_{1}}{\partial w_{1}} w_{1}-v_{1}\right)}{w_{1}^{2}}
$$

These are not very restrictive conditions. Therefore, we conclude that,

More productive workers will invest less time in privilege seeking activities and have a smaller chance of reaching the position of vice-president and thus the position of president.

In state enterprises in which the compensation of a top manager relative to the wage of a low-level worker is relatively low or the wage on each rung is fixed and not a function of the worker's productivity level, then more productive workers have a lower probability of being on a higher rung of the firm.

\section{The Structure of the Firm}

In this section we consider the consequences of the structure of the state enterprise on promotion.

Increasing the number of rungs in the firm without changing the number of employees will increase the number of employees on the different rungs. If the firm contains $n$ vice-presidents competing for the post of president, then the expected income of vice-president $j$ will be, 


$$
E\left(I_{j} \mid n\right)=w_{j}\left(1-L_{j}\right)+w_{j}\left(1-\frac{L_{j}}{\sum_{i=1}^{n} L_{i}}\right)+p_{j} \frac{L_{j}}{\sum_{i=1}^{n} L_{i}} \quad \forall i=1,2, . ., n
$$

Thus:

$$
\frac{\partial E\left(I_{j} \mid n\right)}{\partial L_{j}}=-w_{j}+\left(p_{j}-w_{j}\right) \frac{\sum_{j \neq i}^{n} L_{i}}{\left(\sum_{k=1}^{n} L_{k}\right)^{2}}=0
$$

In order to simplify our analysis, assume that $p_{i}=w_{i}+c .{ }^{4}$ When an employee changes from vise-president to president, his income per unit of productive time increases by a constant, $c$. This increase in productivity is identical for all employees regardless of initial productivity. Less productive workers evidently invest more in rent seeking. ${ }^{5}$

Solving the $n$ first order conditions, we obtain:

$$
L_{j}(n)=\frac{(n-1) c\left(\sum_{i \neq j} w_{i}-(n-2) w_{j}\right)}{\left(\sum_{k=1}^{n} w_{k}\right)^{2}} \forall i=1,2, . ., n
$$

Hence,

rent seeking decreases as productivity increases.

We now calculate the probability that a vice-president will succeed to the post of president:

$$
\operatorname{Pr} o b_{j}(n)=\frac{L_{j}}{\sum_{i=1}^{n} L_{i}}=\frac{\sum_{i \neq j} w_{i}-(n-2) w_{j}}{\sum_{k=1}^{n} w_{k}}
$$

${ }^{4}$ Notice that this example fits the case of a state enterprise as stated in the previous section

${ }^{5}$ The elasticity of the level of productivity of a president with respect to a change in the level of productivity of the worker is less than one. 
Denote the least efficient employee by index j. If we increase the number of vicepresidents from $n$ to $n+1$ by adding a vice-president who is more productive than employee $\mathrm{j}$, then the increase in the probability will be,

$$
\operatorname{Pr} o b_{j}(n+1)-\operatorname{Pr} o b_{j}(n)=-\frac{\sum_{i=1}^{n} w_{i}-(n-1) w_{n+1}}{n(n-1) \sum_{k=1}^{n} w_{k} \sum_{k=1}^{n+1} w_{k}}
$$

If $\operatorname{Prob}_{j}(n) \geq 0$ we obtain that $\operatorname{Prob}_{j}(n+1)-\operatorname{Prob}_{j}(n)<0$ for all $j$. In other words, increasing the number of vice-presidents who are competing for the post of president decreases the probability that each of the existing vice-presidents will succeed to the post. We may conclude that:

As the number of employees competing for the same post increases, the probability of success for the least efficient employee decreases, while the probability that a more productive employee succeeds to the post increases.

In order to understand the results let us examine at the following two cases: A: A three rung firm. This is the model presented above in which 4 workers are divided into 2 groups. From each group one vice-president will emerge and from the two vice-presidents one president will emerge.

B: A two rung firm of 4 workers all in one group that compete for the position of president (the firm does not have any vice-presidents).

Since the first case has been dealt with extensively in the previous section, we focus on the second case. Given that each worker has a productivity of $w_{i}(i=1,2,3,4)$ each worker has an expected income of:

$$
E\left(I_{i}\right)=w_{i}\left(1-L_{i}\right)+w_{i}\left(1-\frac{L_{i}}{\sum_{j=1}^{4} L_{j}}\right)+p_{i} \frac{L_{i}}{\sum_{j=1}^{4} L_{j}} \quad \forall i=1,2, . ., 4
$$

where the expected value depends upon the probability of reaching the position of president or staying in the same position on the first rung. 
Thus,

$$
\frac{\partial E\left(I_{i}\right)}{\partial L_{i}}=-w_{i}+\left(p_{i}-w_{i}\right) \frac{\sum_{j \neq i} L_{j}}{\left(\sum_{k=1}^{4} L_{k}\right)^{2}}=0
$$

As stated above we simplify matters and assume that $p_{i}=w_{i}+c$. Solving the four first order conditions, we obtain,

$$
L_{i}=\frac{3 c\left(\sum_{j \neq i} w_{j}-2 w_{i}\right)}{\left(\sum_{k=1}^{4} w_{k}\right)^{2}} \forall i=1,2,3,4
$$

The probability of a worker winning the contest and becoming the president of the state firm is,

$$
\operatorname{Pr} o b_{i}\left(L_{1}, L_{2}, L_{3}, L_{4}\right)=\frac{L_{i}}{\sum_{j=1}^{4} L_{j}}=\frac{\sum_{j \neq i} w_{j}-2 w_{i}}{\sum_{j=1}^{4} w_{j}}
$$

Once again, more productive workers invest less in rent seeking. Moreover, as the productivity of worker $k(k \neq i)$ increases, the probability of worker $i$ 's gaining the position of president increases:

$$
\frac{\partial \operatorname{Pr} o b_{i}(.)}{\partial w_{i}}<0 \text { and for all } k \neq i \quad \frac{\partial \operatorname{Pr} o b_{i}(.)}{\partial w_{k}}>0
$$

Let us now compare a two rung with a three-rung firm. Assume for a two rung firm that:

$$
c=4, w_{1}=3 \text { and } w_{2}=w_{3}=w_{4}=4
$$

In this case:

$$
\begin{gathered}
L_{1}=0.32, L_{2}=L_{3}=L_{4}=0.16 \\
\text { and } \\
\operatorname{Pr} o b_{1}(.)=0.4, \operatorname{Pr} o b_{2}(.)=\operatorname{Pr} o b_{3}(.)=\operatorname{Pr} o b_{3}(.)=0.2
\end{gathered}
$$

Here the less productive worker is spending $32 \%$ of his time in rent seeking, while the productive workers are investing only $16 \%$ of their time in rent seeking.

For a 3-rung firm, assume: 


$$
\begin{gathered}
w_{1}=3, w_{2}=w_{a}=w_{b}=4, p_{1}=7, p_{2}=p_{a}=p_{b}=8 \\
\text { and } \\
v_{i}=w_{i}+w_{i}^{1 / 2}: \\
v_{1}=4.73, \quad v_{a}=v_{2}=v_{b}=6
\end{gathered}
$$

We obtain:

$$
\begin{gathered}
L_{1}^{1}=0.39, \quad \begin{array}{l}
L_{2}^{1}=0.37, \quad L_{a}{ }^{1}=L_{b}^{1}=0.37 \\
\text { and }
\end{array} \\
\operatorname{Pr} o b_{1}{ }^{1}=0.51, \quad \operatorname{Pr} o b_{2}{ }^{1}=0.49, \quad \operatorname{Pr} o b_{2}{ }^{1}=\operatorname{Pr} o b_{b}{ }^{1}=0.5
\end{gathered}
$$

Given that worker number 1 is to become a vice-presdent, he or she will compete against either employee $a$ or $b$ for the position of president (notice that for our calculations it does not make a difference which of the two become vice-president, as the two are identical as far employee number 1 is concerned):

$$
L_{1}^{2}=0.37, L_{a}^{2}=0.33 \text { and } \operatorname{Pr} o b_{1}{ }^{2}=0.53, \operatorname{Pr} o b_{a}{ }^{2}=0.47 .
$$

Now compare the two types of firms. To simplify, call the two-rung firm I and the three-rung firm II. We see that the probability of a less productive worker becoming a president of the state enterprise is higher in firm I $(0.4)$ than in firm II $(0.51 * 0.53=$ 0.27). Notice, however, that the probability of success for the less productive worker at each stage in the contest is higher in firm number II than in firm number I. This worker will evidently have a greater chance of winning in firm number II than in firm I. It is clear then that in firm II there is a higher probability of a less productive worker (better rent seeker) attaining one of the higher positions in the firm (vice-president and/or president). Looking at the level of investment in rent seeking, we see that in firm I all employees invest more in rent seeking at each stage than in firm II. We conclude that:

1. The firm with the larger internal hierarchy is on average less efficient, because of the greater probability that at each level of contest less productive employees gain promotion. 
2. In a lower-hierarchy firm, all employees (whether they are more or less productive) expend more time in internal rent seeking.

\section{Conclusions}

This paper has investigated who is promoted to senior management in hierarchical firms, as typified by the state enterprise, and whether there is adverse selection in the promotion contests. If the rewards from climbing the ladder in the firm's hierarchy are high but not high enough, less productive employees will be on higher rungs of the firm, reducing efficiency and decreasing rents available to be divided among the employees. The larger the internal hierarchy the lower the efficiency of the firm, on average, because of the greater probability that at each contest level more proficient rent seekers win promotion. On the other hand, in smaller-hierarchy firms all employees expend more time in rent seeking. We thus have a reason for the revealed inefficiency in state enterprises.

We have discussed the state enterprise as the prototype of the hierarchical firm. Our model is may be generalized to a number of firms types, and will be most successful in explaining behavior in firms with a rigid hierarchical structure, in firms that possess diffuse goals, and in firms where there are potentially a large amount of rents generated. Thus the inefficiency of the public sector and the development of "sick" industries and firms are partly explained by our model. Senior management in these firms spends too much time controlling their environment. In the Soviet firm (Berliner (1957) and Granick (1954)), the Communist Party was the recruiting ground for senior management. By the time workers reached the rung in the firm's job ladder in which they had serious responsibility, they were already functioning member of the Communist Party. The inefficiency of the Soviet firm, is thus party explained by the structure of the firm and the activities in which one needed to engage in order to win promotion.

We suggest a different explanation for the incompetency of senior management in bureaucratic organizations than is offered by the Peter Principle. The Peter Principle argues that in hierarchical organizations people are promoted in order to reward them for their (good) performance. Therefore, they are promoted until they reach their 
"level of incompetence" in the firm, and are stuck in that level, since another bureaucratic rule is that people never get demoted. Our argument is not that the good people are being "over-promoted", but that, for the most part, the good people are always "over-looked" for promotion. Those people who are not especially good at producing spend their time in promotion seeking activities (which are not productive). It is these people who earn the promotions. If these people are generally incompetent (a bad worker makes a bad manager), this is bad for the firm, raising its inefficiency. 


\section{References}

Beckmann, M. J. (1978), Rank in Organizations, Berlin: Springer-Verlag.

Berliner, Joseph S., (1957), Factory and Manager in the USSR, Harvard University Press, Cambridge.

Epstein, G. S., (1996a) "Changing a Decision Taken Under Incomplete Information During the Process of Execution", Journal of Economic Behavior and Organization, Vol. 29, pp. 323-329.

Epstein, G. S., (1996b) "The Extraction of a Natural Resource from Two Sites Under Uncertainty" Economics Letters, Vol. 51 (3), pp. 309-313.

Epstein, G. S., Hillman A. L. and Ursprung H. W. (1999) "The King Never Emigrates", Review of Development Economics, 1999, 3(2), pp. 107-121.

Granick, David (1954), Management of the Industrial Firm in the USSR, Columbia University Press, New York.

Hillman, A.L. and Riley, J.G. (1989), "Politically Contestable Rents and Transfers", Economics and Politics, 1, 17-39.

Hirshleifer, J. (1989), "Conflict and Rent Seeking Success functions: Ratio Vs Difference Model of Relative Success" Public Choice, pp. 101-112.

Keren, M. and Levhari, D. (1989), "Decentralization, Aggregation, Control Loss and Costs in Hierarchical Model of the Firm" Journal of Economic Behavior and Organization, pp. 213-236.

Keren, M. and Levhari, D. (1979), "The Optimum Span of Control in Pure Hierarchy", Management Science, pp. 1162-1172.

Radner, R. (1993), "Hierarchy: The Economics of Managing", Journal of Economic Literature, pp. 1382-1415.

Rosen S. (1986), "Prizes and incentives in Elimination Tournaments", The American Economic Review, 76(4), pp. 701-715.

Sah, K. R. and Stiglitz, J. E. (1986), "The Architecture of Economic Systems: Hierarchies and Polyarchies", American Economic Review, pp. 716-723.

Tullock, G. (1980), "Efficient Rent Seeking” In J.M. Buchanan, R.D. Tollison, and G. Tullock, editors, Toward a Theory of the Rent Seeking Society (Texas A\&T Press, College Station TX).

Williamson, O.E. (1967), "Hierarchical Control and Optimum Firm Size", Journal of Political Economy, 75, pp. 123-138. 